
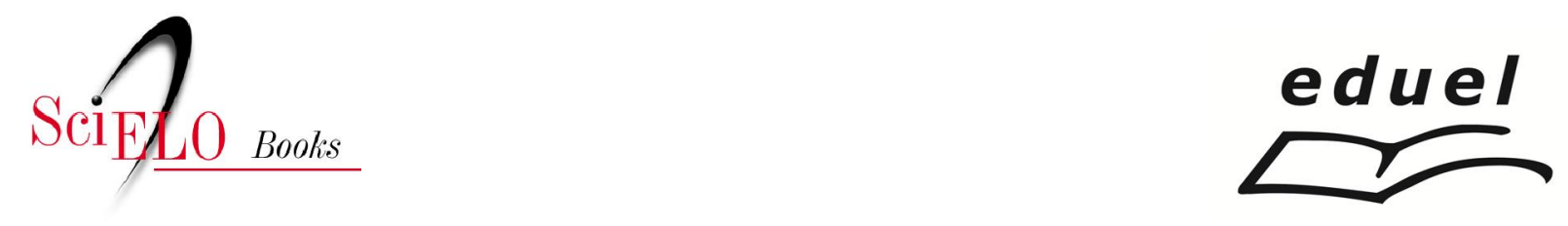

\title{
Tratamento farmacológico do tabagismo
}

\author{
Sandra Odebrecht Vargas Nunes \\ Heber Odebrecht Vargas \\ Luciana Vargas Alves Nunes \\ Mariane Vargas Nunes Noto
}

\section{SciELO Books / SciELO Livros / SciELO Libros}

NUNES, SOV., et al. Tratamento farmacológico do tabagismo. In NUNES, SOV., and CASTRO, MRP., orgs. Tabagismo: Abordagem, prevenção e tratamento [online]. Londrina: EDUEL, 2011. pp. 185-191. ISBN 978-85-7216-675-1. Available from SciELO Books < http://books.scielo.org $>$.

\section{(1) (1)}

All the contents of this work, except where otherwise noted, is licensed under a Creative Commons Attribution-Non Commercial-ShareAlike 3.0 Unported.

Todo o conteúdo deste trabalho, exceto quando houver ressalva, é publicado sob a licença Creative Commons Atribuição Uso Não Comercial - Partilha nos Mesmos Termos 3.0 Não adaptada.

Todo el contenido de esta obra, excepto donde se indique lo contrario, está bajo licencia de la licencia Creative Commons Reconocimento-NoComercial-CompartirIgual 3.0 Unported. 


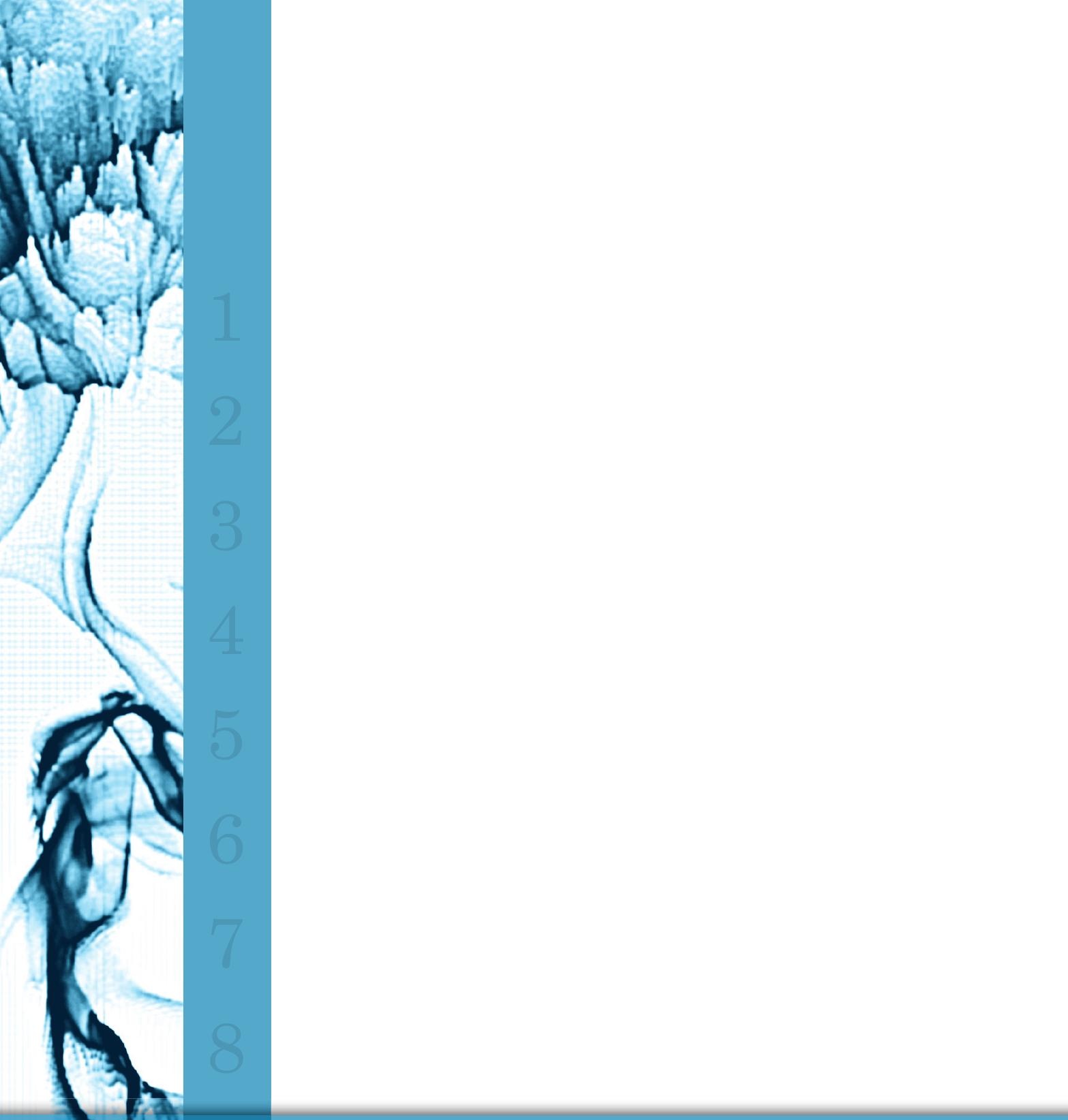

9 Tratamento Farmacológico Do Tabagismo 


\section{Tratamento Farmacológico do Tabagismo}

Sandra Odebrecht Vargas Nunes Heber Odebrecht Vargas Luciana Vargas Alves Nunes Mariane Vargas Nunes Noto

\section{INTERVENÇÕES FARMACOLÓGICAS QUE \\ FACILITAM O CESSAR DE FUMAR}

Fumar cigarros causa dependência definida como um padrão de abuso de droga, caracterizado por envolvimento irresistível com o uso da substância e tendência à recidiva após a interrupção e uma dependência que é um estado fisiológico de neuroadaptação, produzido pela administração repetida da droga, necessitando da administração para prevenir o surgimento da síndrome de abstinência. (STAHL, 2002).

O tratamento do fumante está entre as intervenções médicas que apresentam as melhores relações custo-benefício. A abordagem do fumante para a cessação de fumar tem como eixo central a intervenção psicoterápica cognitivo-comportamental, e em casos específicos, a utilização de apoio medicamentoso. (BRASIL, 2001).

O tratamento farmacológico deixou de ser um acessório do tratamento psicológico para ser um instrumento terapêutico que duplica a chance de êxito. (FERREIRA, 2007).

Os métodos de tratamento preconizados como primeira linha são a terapia de reposição de nicotina, a utilização de bupropiona e a terapia cognitivo-comportamental em grupo ou individual. (AMERICAN PSYCHIATRIC ASSOCIATION, 1996; BRASIL, 2001; MARQUES et al., 2001).

O uso de medicamentos é um recurso adicional no tratamento do tabagismo quando a abordagem comportamental é insuficiente, pela presença de comorbidades psiquiátricas ou quando o grau de dependência à nicotina é elevado. Os fármacos com evidências de eficácia são classificados em nicotínicos e não nicotínicos. A terapia 
de reposição de nicotina ( $\mathrm{TRN})$, a bupropiona e a vareniclina são consideradas de primeira linha, enquanto que a nortriptilina e a clonidina são os fármacos de segunda linha no tratamento. (REICHERT et al., 2008).

Os médicos, além da intervenção breve para cessar o consumo do tabaco, podem oferecer os tratamentos farmacológicos que não tenham contraindicação, sumarizados no quadro 19:

\begin{tabular}{|l|l|l|}
\hline \multicolumn{1}{|c|}{ VANTAGENS } & \multicolumn{1}{c|}{ DESVANTAGENS } & \multicolumn{1}{c|}{ CONTRAINDICAÇÕES } \\
\hline $\begin{array}{l}\text { Bupropiona: } 150 \mathrm{mg} \text { por } 3 \text { dias } \\
\text { e após, } 300 \mathrm{mg} \text { por dia por } \\
12 \text { semanas. Fácil de usar. } \\
\text { Começar } 1 \text { a } 2 \text { semanas antes } \\
\text { de cessar o consumo. }\end{array}$ & $\begin{array}{l}\text { Pode causar insônia, } \\
\text { boca seca, dor de cabeça, } \\
\text { tremores, náuseas, } \\
\text { ansiedade. }\end{array}$ & $\begin{array}{l}\text { Gravidez categoria B: } \\
\text { Evitar em pacientes epiléticos, } \\
\text { com bulimia e anorexia, } \\
\text { história de trauma cerebral } \\
\text { e em uso de antidepressivos } \\
\text { IMAO. }\end{array}$ \\
\hline $\begin{array}{l}\text { Goma de nicotina para } \\
\text { pacientes que fumam cerca de } \\
15 \text { cigarros por dia. Uma goma } \\
\text { de } 2 \text { mg a cada } 1 \text { ou } 2 \text { horas. }\end{array}$ & $\begin{array}{l}\text { Nenhuma comida ou bebida } \\
\text { antes de } 15 \text { minutos de uso. } \\
\text { Pode causar dor mandibular } \\
\text { e dispepsia. }\end{array}$ & $\begin{array}{l}\text { Gravidez categoria D: } \\
\text { Evitar em pacientes } \\
\text { com problemas dentais } \\
\text { ou da articulação } \\
\text { temporomandibular. }\end{array}$ \\
\hline $\begin{array}{l}\text { Adesivo de Nicotina com mais } \\
\text { de } 10 \text { cigarros por dia: utilizar } \\
\text { adesivo de } 21 \text { a cada } 24 \text { horas } \\
\text { por } 6 \text { a } 8 \text { semanas; abaixo de } 10 \\
\text { cigarros, } 14 \text { mg cada } 24 \text { horas } \\
\text { por } 2 \text { a } 4 \text { semanas e após, } 7 m g \\
\text { cada } 24 \text { horas por } 24 \text { semanas. }\end{array}$ & $\begin{array}{l}\text { Pode causar irritação de pele } \\
\text { ou problemas de sono. }\end{array}$ & $\begin{array}{l}\text { Gravidez categoria D: } \\
\text { Precauções com problemas } \\
\text { cardiovasculares. }\end{array}$ \\
\hline
\end{tabular}

Quadro 19 - Intervenções farmacológicas que facilitam cessar o tabaco. Fonte: (OKUYEMI; NOLLEN; AHLUWALIA, 2006).

Por envolver vários fatores, o tratamento da dependência da nicotina deve ter sua escolha baseada em eficácia, segurança, perfil dos efeitos colaterais, custo, tratamentos anteriores e gravidade do caso. Além disso, fundamental levar em consideração a situação econômica e a motivação do paciente. (GIGLIOTTI; OLIVEIRA; LARANJEIRA, 2006). 
A terapia de reposição de nicotina pode ser usada como abordagem de primeira linha para qualquer pessoa que deseje parar de fumar, e é eficaz no alívio dos sintomas de abstinência. Existem cinco formas aprovadas pelo FDA: adesivo, goma, pastilha, spray nasal e inalador. (AMERICAN PSYCHIATRIC ASSOCIATION, 2008).

As terapias de reposição de nicotina através da goma de mascar e do adesivo transdérmico foram indicadas nos atendimentos individuais para aliviar a síndrome de abstinência e facilitar a abordagem cognitivo-comportamental. As situações potenciais para a utilização do apoio medicamentoso são: pacientes que fumam 20 ou mais cigarros por dia; pacientes que fumam o primeiro cigarro até 30 minutos após acordar e fumam no mínimo 10 cigarros por dia; pacientes com Teste de Fagerström igual ou maior que 5; pacientes que tentaram parar com abordagem cognitivo-comportamental e não conseguiram devido a sintomas de abstinência insuportáveis e por não haver contraindicações clínicas. As contraindicações e precauções de reposição de nicotina eram: gravidez, menores de 18 anos, amamentação, história de úlcera péptica, passado de infarto do miocárdio, angina, arritmia cardíaca, derrame cerebral. (BRASIL, 2001).

Várias metanálises apontam a reposição de nicotina como sendo eficaz no tratamento do tabagismo, uma vez que ela duplica as taxas de sucesso tanto de terapias breves quanto de abordagens intensivas e, até mesmo, quando usada sem acompanhamento clínico. (FERREIRA, 2007).

\section{BUPROPIONA}

A bupropiona é um antidepressivo que tem como mecanismo de ação inibir a recaptação de dopamina e noradrenalina no sistema nervoso central.

A associação da terapia de reposição de nicotina com a bupropiona foi utilizada em alguns fumantes, resultando em um 
aumento da efetividade na cessação do uso do tabaco, quando comparada ao uso de bupropiona isoladamente. (AMERICAN PSYCHIATRIC ASSOCIATION, 1996).

A bupropiona deverá ser iniciada uma semana antes de cessar o consumo. A dose inicial é de $150 \mathrm{mg} /$ dia até o terceiro dia, passando para $300 \mathrm{mg} /$ dia por 12 semanas. O mecanismo de ação é mediado pela noradrenalina e pela dopamina, agindo diretamente na diminuição da fissura ou craving. As contraindicações são: pessoas epiléticas, uso concomitante de compostos contendo bupropiona, retirada recente de álcool, traumatismo cranioencefálico, uso concomitante de inibidores da monoaminoxidase e transtornos alimentares. (MARQUES et al., 2001).

A associação da terapia de reposição de nicotina com a bupropiona ou nortriptilina tem resultado em um aumento da efetividade na cessação do uso do tabaco, quando comparada ao uso de antidepressivos isoladamente. (AMERICAN PSYCHIATRIC ASSOCIATION,1996).

A bupropiona está indicada para adultos que consomem 15 cigarros ou mais ao dia. Para fumantes com depressão, a indicação fica mais interessante e precisa. (AMERICAN PSYCHIATRIC ASSOCIATION, 1996; BRASIL, 2001; MARQUES et al., 2001).

\section{NORTRIPTILINA}

A nortriptilina tem um mecanismo de ação de inibir a recaptação de noradrenalina e dopamina no sistema nervoso central, reduzindo os sintomas depressivos e os efeitos da síndrome de abstinência da nicotina.

A nortriptilina tem eficácia no tratamento para a dependência de nicotina; entretanto, dado o número de outros tratamentos disponíveis cujos resultados têm boa validação, essa droga deve ser considerada como terapia de segunda linha. (AMERICAN PSYCHIATRIC ASSOCIATION, 2008). 


\section{CLONIDINA}

A clonidina alivia os sintomas de abstinência como irritabilidade, cansaço e fissura, quando utilizada na dose de 0,1 até $0,75 \mathrm{mg}$ por dia, por aproximadamente três semanas. (GIGLIOTTI; OLIVEIRA; LARANJEIRA, 2006).

\section{VARENICLINA}

A vareniclina é um agonista parcial do receptor nicotínico a462 de acetilcolina, e seu mecanismo de ação é o de abrandar a urgência de fumar e os efeitos de reforço do tabagismo. (KEATING; SIDDIQUI, 2006). O desenvolvimento da vareniclina foi baseado no alcaloide citisina, que ocorre naturalmente e havia mostrado efeito agonista parcial para os receptores colinérgicos a 462, tendo sido considerada uma droga eficaz, segura e bem tolerada nas doses recomendadas para os pacientes em processo de cessação do tabagismo. (REICHERT et al., 2008).

Os agonistas parciais a 462 de acetilcolina poderiam estimular a liberação de dopamina suficiente para reduzir o desejo e a abstinência enquanto, simultaneamente, agiriam como antagonistas parciais por meio de bloqueio de ligação e dos consequentes efeitos de recompensa da nicotina consumida antes do cigarro.

A vareniclina foi significativamente mais eficaz do que placebo para parar de fumar. Nos fumantes que conseguiram abstinência por, pelo menos, sete dias no final do tratamento de 52 semanas, o índice de abstinência da vareniclina foi quase 2,5 vezes o de placebo, apresentou-se similar em homens e mulheres e se manteve até de 24 a 52 semanas. (GONZALES et al., 2006). Em um estudo clínico randomizado, os fumantes que abandonaram o hábito tabagista com sucesso depois de receber esquema aberto com vareniclina por 12 semanas iniciais apresentaram um índice bastante menor de recaídas ao tomar vareniclina $1 \mathrm{mg} 2$ vezes por dia, por mais 12 semanas, em comparação com quem tomou o placebo. (TONSTAD et al., 2006). 


\section{PROPOSTA FUTURA: IMUNOTERAPIA}

As vacinas contra a nicotina agem estimulando o sistema imunológico a produzir anticorpos específicos que se ligam com grande afinidade à nicotina no plasma e em líquidos extracelulares.

A nicotina, ao ligar-se aos anticorpos, não consegue atravessar a barreira hematoencefálica devido ao seu tamanho, e assim se rompe o círculo vicioso da gratificação produzida no nível cerebral. (REICHERT et al., 2008).

\section{REFERÊNCIAS}

AMERICAN PSYCHIATRIC ASSOCIATION. Practice guideline for the treatment of patients with nicotine dependence. American Journal of Psychiatry, Washington, v.151, p. 1-31, 1996.

AMERICAN PSYCHIATRIC ASSOCIATION. Manual Diagnóstico e Estatístico de Transtornos Mentais: DSM-IV-TR. 4.ed. rev. Porto Alegre: Artmed, 2003.

Diretrizes par o tratamento de transtornos Psiquiátricos compêndio 2006. Porto Alegre: Artmed, 2008.

BRASIL. Ministério da Saúde. Instituto Nacional de Câncer. Abordagem e tratamento do fumante. Rio de Janeiro: INCA, 2001.

FERREIRA, M. P. Tabagismo. In: LOUZÃ NETO, M. R.; ELKIS, H. Psiquiatria Básica. 2.ed. Porto Alegre: Artmed, 2007.

GIGLIOTTI, A.; OLIVEIRA, C.; LARANJEIRA, R. Atualização no tratamento farmacológico do tabagismo. In: GIGLIOTTI, A.; PRESMAN, S. Atualização no tratamento do tabagismo. Rio de Janeiro: ABPSaúde,2006.

GONZALES, D. et al. Varenicline an $\alpha 4 \beta 2$ nicotinic acetylcholine receptor partial agonist, vs sustained -release bupropion and placebo for smoking cessation : a randomized controlled trial. JAMA, [s.l.], v.296, p..47-55, 2006. 
KEATING, G. M.; SIDDIQUI, M. A. Varenicline: a review of its Use as an aid to smoking cessation therapy. Drugs, New York, v. 20, n. 11, p.945960, 2006.

MARQUES, A. C. P. R. et al. Consenso sobre o tratamento da dependência de nicotina. Revista Brasileira de Psiquiatria, São Paulo, v. 23, n. 4, p. 200-214, 2001.

OKUYEM, K. I.; NOLLEN, N.; AHLUWALIA, J. Interventions to facilitate Smoking Cessation. American Family Physician, v.74, p.262-71, 2006.

REICHERT, J. et al. Diretrizes da SBPT - Diretrizes para cessação do tabagismo - 2008. J Bras Pneumol. [s.1.], v. 34, n. 10, p. 845-8, 2008.

STAHL, S. Psicofarmacologia: Base neurocientífica e aplicações práticas. 2.ed. Rio de Janeiro: MEDSI, 2002.

TONSTAD, S.; TONNRDRN, P.; HAJEK, P.; WILLIAM, K.; BILING, C.; REEVES, K. Effect of varenicline on smoking cessation. JAMA, [s.l.], v.296, p.64-71, 2006. 
